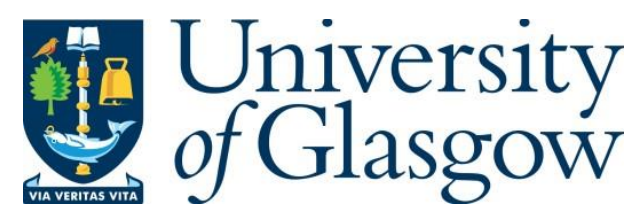

Macklin, P. S., Hall, A., Lee, J., Hair, J., Spiers, V., Thomas, G. J., Oien, K. A. and Verrill, C. (2018) Barriers to the release of human tissue for clinical trials research in the UK: a national survey of cellular pathology laboratories on behalf of the National Cancer Research Institute's Cellular Molecular Pathology (CM-Path) initiative. Journal of Clinical Pathology, 72(1), pp. 52-57.

There may be differences between this version and the published version. You are advised to consult the publisher's version if you wish to cite from it.

http://eprints.gla.ac.uk/206260/

Deposited on: 12 February 2020

Enlighten - Research publications by members of the University of Glasgow http://eprints.gla.ac.uk 


\section{Barriers to the release of human tissue for clinical trials research in the United Kingdom: a national survey of cellular pathology laboratories on behalf of the National Cancer Research Institute's Cellular Molecular Pathology (CM-Path) initiative} Macklin PS ${ }^{1}$, Hall $\mathrm{A}^{2}$, Lee $\mathrm{J}^{3}$, Hair $\mathrm{J}^{4}$, Speirs $\mathrm{V}^{5^{*}}$, Thomas $\mathrm{JJ}^{6}$, Oien KA ${ }^{7}$, Verrill $\mathrm{C}^{1,8}$

${ }^{1}$ Department of Cellular Pathology, Oxford University Hospitals NHS Trust, Oxford, UK

${ }^{2}$ Northern Institute for Cancer Research, Newcastle University, Newcastle upon Tyne, UK

${ }^{3}$ Strategy and Initiatives, National Cancer Research Institute, London, UK

${ }^{4}$ Greater Glasgow and Clyde Bio-repository, Department of Pathology, Queen Elizabeth University Hospital, Glasgow, UK

${ }^{5}$ Leeds Institute of Cancer and Pathology, University of Leeds, Leeds, UK

${ }^{6}$ Cancer Sciences Unit, University of Southampton, Southampton, UK

${ }^{7}$ Department of Pathology, Southern General Hospital, Glasgow, UK

${ }^{8}$ Nuffield Department of Surgical Sciences, University of Oxford, and NIHR Oxford Biomedical Research Centre, Oxford, UK

${ }^{*}$ Present address - Institute of Medical Sciences, University of Aberdeen, Aberdeen, UK

Corresponding authors:

Philip Macklin

philip.macklin@ouh.nhs.uk

\author{
Clare Verrill \\ clare.verrill@nds.ox.ac.uk
}

+44 (0)1865220150 


\author{
Authors' contributions: \\ Conceptualisation - PSM, AH, JH, VS, GJT, KAO, CV \\ Methodology - PSM, AH, JH, VS, GJT, KAO, CV \\ Investigation - PSM, JL \\ Formal analysis - PSM, CV \\ Resources - PSM, JL \\ Data curation - PSM, JL \\ Writing - original draft - PSM, CV \\ Writing - review \& editing - PSM, AH, JL, JH, VS, GJT, KAO, CV \\ Visualisation - PM \\ Supervision - CV \\ Project administration - JL \\ Funding acquisition - not applicable
}

Conflict of interest statements:

Philip Macklin has nothing to disclose.

Andrew Hall has nothing to disclose.

Jessica Lee has nothing to disclose.

Jane Hair has nothing to disclose.

Valerie Speirs has nothing to disclose.

Gareth Thomas has nothing to disclose.

Karin Oien reports grants from National Cancer Research Institute, during the conduct of the study; grants from Leica Biosystems, grants from Qiagen, non-financial support from ThermoFisher, non-financial support from Illumina, non-financial support from Aridhia, non- 
financial support from Sistemic, non-financial support from BioClavis, non-financial support from Biotheranostics, outside the submitted work.

Clare Verrill reports other from National Cancer Research Institute CM-Path, other from NIHR Oxford Biomedical Research Centre (BRC), other from CRUK Oxford Cancer Centre, during the conduct of the study.

Ethics committee approval:

Not applicable.

Funding:

The NCRI's CM-Path initiative was established in 2016 with the aim of re-invigorating academic pathology. It is funded as a collaborative venture between ten of the NCRI partner organisations: Bloodwise, Breast Cancer Now, Cancer Research UK, the Chief Scientist Office (Scotland), the Department of Health and Social Care (England), Health and Care Research Wales, Health and Social Care (Northern Ireland), the Medical Research Council, Prostate Cancer UK and Tenovus Cancer Care. These organisations did not participate in study design; collection, analysis and interpretation of data; writing the report or the decision to submit the paper for publication.

Word counts:

Abstract -181 words

Manuscript - 2983 words 


\author{
Abstract \\ Aim \\ To survey United Kingdom (UK) cellular pathology departments regarding their attitudes \\ and practices relating to release of human tissue from their diagnostic archives for use in \\ clinical trial research.

\section{Methods}

A 30-item questionnaire was circulated to the National Cancer Research Institute's (NCRI) Cellular Molecular Pathology Initiative (CM-Path) and Confederation of Cancer Biobanks (CCB) mailing lists. Responses were collected over a ten-month period from November 2016 to August 2017.

Results

38 departments responded to the survey, the majority of which regularly receive requests for tissue for research purposes. Most requests come from academia and financial support to facilitate tissue release comes from a variety of sources. A range of practices were reported in relation to selection of the most appropriate sample to release, consent checking, costings and governance frameworks.

\title{
Conclusions
}

This survey demonstrates wide variation in practice across the UK and identifies barriers to release of human tissue for clinical trial research. Until we can overcome these obstacles, patient samples will remain inaccessible to research. Therefore, this study highlights the urgent need for clear and co-ordinated national guidance on this issue. 


\section{$\underline{\text { Introduction }}$}

Straddling the interface between basic research and medical practice, clinical trials play a vital role in improving healthcare [1]. Tissue-based analyses are critically important in trials [2-4]; for example, pathology review for trial entry or outcome determination and biomarker testing to inform treatment allocation. Unfortunately, there are often difficulties in obtaining human tissue for research [5]. In the United Kingdom (UK), human tissue samples are collated by both National Health Service (NHS) cellular pathology laboratories and academic biobanks. Access to tissue stored in biobanks is usually straight forward since such samples are collected for research; the situation is different, however, for the release of tissue from NHS diagnostic archives. Archived diagnostic material is usually held as formalin-fixed paraffin-embedded (FFPE) blocks, with the Royal College of Pathologists (RCPath) recommending retention for 30 years after initial diagnosis [6]. These guidelines acknowledge a tension between retention of surplus material for the patient's future benefit and its immediate use for research. This is particularly relevant given the recent explosion of novel molecular tests that can be applied to stored tissue to direct treatment upon disease recurrence $[7,8]$; however, it is envisaged that this need will decline as more testing is undertaken at the time of diagnosis $[9,10]$. Ultimately, RCPath recommends that decisions are taken on a case-by-case basis.

The legal and administrative frameworks underpinning tissue release from diagnostic archives for research are also complex. Under the Human Tissue Act (2004), the Human Tissue Authority (HTA) must license the storage of relevant material for research [11]. If tissue is released from a diagnostic archive on a regular basis, it is considered a Research Tissue Bank (RTB) and requires a HTA license. However, HTA licensing is not required if a 
diagnostic archive only occasionally releases tissue upon request. The mechanisms responsible for managing the release of archival material for research also vary; whilst some centres have dedicated tissue access committees, in others laboratory staff oversee the process.

Given the importance of tissue release for clinical trial research, and to understand why this is not always achieved, the National Cancer Research Institute's (NCRI) Cellular Molecular Pathology (CM-Path) initiative surveyed the UK's cellular pathology laboratories to ascertain current attitudes and practices.

\section{Methods}

Our survey was developed by CM-Path Clinical Trials workstream members, based on their own experiences and a similar study conducted in the United States of America (USA) [12]. It contained 30 questions with the aim of assessing: (1) current attitudes and practices; (2) financial implications; and (3) barriers to tissue release (Appendix 1). The survey was distributed through the NCRI's CM-Path and Confederation of Cancer Biobanks (CCB) mailing lists using an online survey tool (www.surveymonkey.com). The questionnaire asked for the most appropriate individual in each department to complete it. We did not specify who this should be but suggestions of a tissue access committee chair or head of department were provided.

The questionnaire was distributed in November 2016, with results analysed in August 2017. To maximise responses, periodic reminder emails were sent and departments that had not completed the survey were contacted. We also contacted several district general hospitals 


\section{$\underline{\text { Results }}$}

Respondents (Q. 1-3)

44 individuals completed the survey, representing 38 different departments/institutions. 6 duplicate responses were excluded from quantitative analyses $(n=38)$ but were included in qualitative analyses ( $n=44)$. Responses were received from throughout the UK (including England, Wales, Scotland and Northern Ireland) and were mostly from university-affiliated hospitals ( $n=26 ; 68.4 \%$ ) with a smaller number from district general hospitals $(n=9 ; 23.7 \%)$ and academic biobanks ( $n=3 ; 7.9 \%)$. Respondents included 10 departmental managers (26.3\%), 7 tissue access committee chairs (18.4\%), 4 clinical heads of department $(10.5 \%)$ and 17 other individuals (44.7\%) including biobank managers, research leads and consultant histopathologists.

Tissue archives (Q. 4-7)

The majority of departments (32;84.2\%) have split on- and off-site archives, 1 department (2.6\%) has a fully off-site collection and 1 collection (2.6\%) is split between multiple NHS sites. Only 3 departments (7.9\%) had fully on-site collections and 1 respondent $(2.6 \%)$ did not answer. Of the 33 departments that store human tissue off-site, $8(24.2 \%)$ felt that this was a barrier to sample release, 24 (72.7\%) did not and 1 (3.0\%) did not know. Amongst 
departments with off-site collections, the cost of retrieving a standard case ranged between £0-50 (mean $£ 21.50$ ). 30 departments (78.9\%) reported that their tissue archives are covered by a HTA licence, 5 (13.2\%) are not, 2 (5.3\%) did not know and 1 (2.6\%) did not reply.

Tissue access (Q. 8-15)

31 departments (81.6\%) regularly receive requests to release human tissue for research (several per month), 5 (13.2\%) occasionally receive requests (1 per month) and $2(5.3 \%)$ did not reply. 25 departments (65.8\%) have a tissue access committee whereas 11 (28.9\%) do not; 2 respondents (5.3\%) did not know whether such a committee existed.

When asked to send tissue for a clinical trial and multiple blocks are available, the following practices were reported (Figure 1):

- Submit paraffin block - 10 (26.3\%);

- Submit paraffin block with conditions (e.g. block must be available for return if required and tissue must not be exhausted) - 13 (34.2\%);

- Submit unstained sections - $5(13.2 \%)$;

- Use histopathologist's discretion - 6 (15.8\%);

- Decline request - 0 (0.0\%);

- Other - 2 (5.3\%, 'would not send multiple blocks');

- $\quad$ No reply -2 (5.3\%).

When only one block is available, responses were:

- Submit paraffin block - $4(10.5 \%)$; 
- Submit paraffin block with conditions - 9 (23.7\%);

- Submit unstained sections - $10(26.3 \%)$;

- Use histopathologist's discretion - 11 (28.9\%);

- Decline request - $0(0.0 \%)$;

- Other $-2(5.3 \%$, one respondent suggested submitting a core of tissue from the block);

- No reply - 2 (5.3\%).

When receiving a request to send diagnostic slides for central review, departments would (Figure 2):

- Submit diagnostic slides (no recuts made) - 22 (57.9\%, several respondents stated they would scan slides prior to dispatch);

- Submit recut slides and keep original diagnostic slides - 8 (21.1\%);

- Submit diagnostic slides and keep recut slides - 0 (0.0\%);

- Submit scanned images of diagnostic slides - 3 (7.9\%);

- Decline request - $0(0.0 \%)$;

- Other -4 (10.5\%, 'a combination of original slides, recuts and scanned images depending upon the particular case' and 'pathologist's discretion');

- No reply -1 (2.6\%).

9 departments (23.7\%) stated that the availability of a mechanism to quickly and easily retrieve blocks upon request and/or to ensure that tissue would not be exhausted would change their willingness to send blocks, 21 (55.3\%) stated that it would not, $6(15.8 \%)$ were unsure and 2 (5.3\%) did not reply. When asked whether release of tissue was dependent 
upon the reporting pathologist's permission, 17 departments (44.7\%) answered 'yes', 19 (50.0\%) 'no' and 2 (5.3\%) did not reply. 25 respondents (65.8\%) felt that there is a duty on pathology departments to maintain diagnostic material for future testing, 8 (21.1\%) felt 'it depends on the specifics of the consent form', 3 (7.9\%) answered 'don't know', 1 (2.6\%) answered 'other' (stating that they believed that it was their duty to facilitate research) and $1(2.6 \%)$ did not reply (Figure 3$)$.

Charges for tissue release (Q. 16-23)

23 departments (60.5\%) charge for sending diagnostic blocks or slides for a trial, 11 (28.9\%) do not and 4 (10.5\%) did not reply (range f8.00-165.00, mean f63.50). 22 departments (57.9\%) charge for cutting sections, 10 (26.3\%) do not, 2 (5.3\%) replied 'other' ('not all the time, depends on the study') and 4 (10.5\%) did not reply (range $f 1.34-15.00$ per block, mean f7.81). 14 departments (36.8\%) charge for scanning sections, 12 (31.6\%) do not, 4 (10.5\%) do not have access to a scanner, 3 (7.9\%) replied 'other' ('not sure') and 5 (13.2\%) did not reply (range $£ 1.00-20.00$ per slide, mean $£ 10.33$ ). When asked 'if you charge for sending materials for research, have the costs been factored in to the research study?', 6 departments (15.8\%) replied 'always', 15 (39.5\%) 'mostly', 11 (28.9\%) 'sometimes', 0 (0.0\%) 'never', 1 (2.6\%) 'other' ('possibly done by the Research and Development department') and $5(13.2 \%)$ did not reply.

2 departments (5.3\%) stated that more than 50\% tissue requests originate from industry, 14 (36.8\%) 5-50\%, $14(36.8 \%)$ less than 5\%, 5 (13.2\%) were unsure and $3(7.9 \%)$ did not reply (Figure 4). 21 departments (55.3\%) charge industry more than academia, 10 (26.3\%) charge the same and 7 (18.4\%) did not reply. 19 departments (50.0\%) would still charge if a study 
was on the National Institute for Health Research (NIHR) trial portfolio, 12 (31.6\%) would not, 2 (5.3\%) replied 'other' ('not sure') and 5 (13.2\%) did not reply.

A variety of funding sources to fulfil research requests were reported (Figure 5):

- NHS - 17 (44.7\%);

- NIHR Biomedical Research Centres - 4 (10.5\%);

- University - 2 (5.3\%);

- $\quad$ Mixed-9 (23.7\%);

- Other-2 2 (5.3\%, 'work completed in-house and costs charged to the project' and 'no specific funding');

- No reply -4 (10.5\%).

Consent issues (Q. 24-28)

When asked 'does your institution have a system of collecting consent wishes in relation to surplus diagnostic material when patients are undergoing surgery on the NHS consent to procedure form?', 16 departments (42.1\%) replied 'yes', 10 (26.3\%) 'no', 10 (26.3\%) 'not sure' and 2 (5.3\%) did not reply. 8/16 departments (50.0\%) who replied 'yes' felt that their system was 'robust', 5 (31.3\%) 'variable', 2 (12.5\%) 'unreliable' and $1(6.3 \%)$ reported that their system was just being set-up and it was too early to judge. 21 departments (55.3\%) have a specific biobank consent form that can be used for surplus diagnostic material, 9 (23.7\%) do not, 6 (15.8\%) were unsure and 2 (5.3\%) did not reply. When asked 'for clinical trials, do you ask to see the consent form before releasing tissue?', 21 departments (55.3\%) replied 'yes, always', 8 (21.1\%) 'yes, if possible', 3 (7.9\%) 'no', 2 (5.3\%) 'other' ('consent checking performed by Research and Development department'), 1 (2.6\%) 'don't know' and 
$3(7.9 \%)$ did not reply (Figure 6). When asked 'for research studies that are not related to a clinical trial, would you require evidence of consent before releasing diagnostic archive material?', 16 departments (42.1\%) replied 'yes, always', 2 (5.3\%) 'yes, if possible', 13 (34.2\%) 'not necessarily if release is for a Research Ethics Committee (REC) approved project, the material is from the living and released anonymously (and you are sure the patient didn't decline)', 0 (0.0\%) 'no', 3 (7.9\%) 'other' ('our own institution's generic REC approval includes the use of the diagnostic archive' and 'split views ... most of us believe that the HTA rules indicate tissue can be used if fully anonymised and that the project is REC approved'), 1 (2.6\%) 'don't know' and 3 (7.9\%) did not reply.

Other information (Q. 29\&30)

When asked 'do you experience any other problems related to submission of materials for clinical trials or other research studies?', a number of comments were provided:

- Underfunding and understaffing in NHS departments;

- Lack of time;

- Poor trial organisation including lack of detail about how samples will be used and/or specific tissue requirements;

- Difficulty accessing relevant documents (e.g. REC applications);

- Problems with consent (tissue release not specified on consent form, inadequate knowledge and lack of communication/education about consent in general);

- Lack of available tissue (particularly small biopsies);

- Difficulties allocating limited material between competing studies;

- Bad experiences after sending blocks away (returned with very little tissue remaining); 
- Increasing numbers of patient-triggered requests to send material to other countries for testing, with significant resource implications.

When asked 'are there any additional comments that you would like to make relating to this topic in general?', the following issues were raised:

- Laboratories do try to fulfil requests but research will always come second to clinical diagnosis in the NHS;

- Need for dedicated staff to fulfil requests (facilitating tissue requests should not be seen as part of a pathologist's 'day job');

- Variable practices within and between centres and lack of overarching guidance;

- Suggestion that it would be helpful to have access to a centralised clinical trial and National Research Ethics Service (NRES) document repository;

- Loss of tissue for local research;

- Frustration when tissue requests are not treated with urgency by other hospitals.

\section{Conclusions}

To our knowledge, this is the first attempt to gather information systematically about the release of tissue from diagnostic archives for clinical trial research in the UK. We received responses from both academic institutions and district general hospitals; with the majority of the UK's teaching hospitals replying we believe that our data represent the practices of departments involved in large scale clinical research. Most institutions (82\%) receive several requests per month for tissue for research. This is likely to place a significant burden on departments, many of which reported lack of funding and understaffing as significant problems. Most requests come from the academic sector but there also appears to be a 
reasonable number from industry who are charged more by most departments. Money to fulfil these requests comes from a variety of sources and in several institutions comes from a combination of funding streams. Whilst part of this variation is likely explained by institutional differences in funding strategies, we are concerned that it may also reflect a more serious issue of general underfunding of pathology support for clinical trials. The NHS is the sole funding source in only $45 \%$ centres, demonstrating the need for additional resources to ensure continued support for trials in the face of increasing diagnostic workloads [14].

Our results also demonstrate wide variation in practices between departments. The majority (87\%) have at least some of their archives located off-site and a sizeable minority of these (24\%) felt that this provided an obstacle to research; furthermore, retrieval of samples incurs additional costs. $61 \%$ departments charge for sending slides or blocks to a trial with a mean of $£ 63.50$ (range $=£ 8-165)$. A similar percentage $(58 \%)$ charge for cutting sections with a mean of $£ 7.81$ per block (range $=£ 1.34-15$ ). Just over half of departments that have access to a scanner $(14 / 26)$ charge for using this equipment with a mean of $£ 10.33$ per slide (range $=£ 1-20)$. Despite this, only 6 departments $(16 \%)$ stated that these costs were always included within trial budgets.

Interestingly, 58\% departments would release their original diagnostic sections for central review whilst only $8 \%$ would submit scanned images. With more departments now having access to a slide scanner [15], this would be an obvious solution to avoid the risk of damage during transit. When multiple blocks exist, $61 \%$ departments would release the block with or without conditions but when only one block exists, this drops to $34 \%$. Simultaneously, the 
$87 \%$ respondents felt that there is at least some duty on departments to maintain diagnostic material for future testing whilst none felt this is not the case. Unfortunate anecdotes described blocks being returned with scanty remaining tissue due to factors such as poor microtomy. Further comments remarked on a 'parasitic' relationship whereby clinical trials depleted tissue for local research. However, only $24 \%$ departments felt that the availability of a mechanism to retrieve blocks quickly upon request and/or to ensure that tissue was not exhausted would change their willingness to send blocks. Nevertheless, better communication between trial centres and pathology departments and clearer arrangements to prevent tissue depletion are likely to encourage a more 'symbiotic' relationship.

Our survey also demonstrates disparity between departments in governance frameworks. Most, but not all, departments (79\%) are covered by an HTA licence. Only 66\% departments have a tissue access committee; indeed, release of tissue is dependent upon the reporting 
pathologist's permission in $45 \%$ departments. Only $55 \%$ respondents were certain that their institution has a specific biobank consent form whilst only $42 \%$ were certain that their hospital's surgical consent form covers this. Furthermore, of these $42 \%$, only half felt that their system is 'robust'. When releasing tissue for clinical trials, 76\% departments would ask to see the consent form. However, this figure falls to $47 \%$ when tissue is being release for studies that are not part of a clinical trial. A lack of knowledge and guidance relating to what constitutes acceptable tissue release practices were flagged as problems and likely explain, at least in part, this variation.

In summary, it appears that the UK's cellular pathology laboratories are committed to facilitating requests for tissue to support clinical trials in the face of considerable challenges. This commitment is critically important since trial enrolment offers patients access to cutting-edge treatments and thus may represent their best chance of cure. No single barrier to the release of tissue was apparent; instead, multiple impeding factors were identified, the most prominent being insufficient staffing and funding and lack of guidance as to what constitutes best practice. In the face of an evolving crisis in the UK's pathology workforce, additional activities such as research are likely to be deprioritised [14]; we believe that specific funding for pathologists must be provided to ensure that their crucial support to trials continues. Our findings provide a springboard for tackling the identified barriers and for generation of national guidelines to facilitate standardisation of best practices.

\section{Key messages}

- Access to human tissue samples is vital to the success of clinical trials and advances in medical science 
- This survey demonstrates a lack of consistency in human tissue release practices across UK pathology departments

- Whilst departments appear to be committed to fulfilling tissue requests, multiple impeding barriers were identified including lack of resources and clear guidance as to what constitutes best practice

- Specific funding for pathologists must be provided to ensure that their crucial support to trials continues

\section{Acknowledgements}

We would like to thank the individuals who took the time to complete our survey. 


\section{References}

1. Krzyzanowska, M.K., R. Kaplan, and R. Sullivan, How may clinical research improve healthcare outcomes? Ann Oncol, 2011. 22 Suppl 7: p. vii10-vii15.

2. Nagtegaal, I.D., et al., Pathology is a necessary and informative tool in oncology clinical trials. J Pathol, 2014. 232(2): p. 185-9.

3. Han, H.S. and A.M. Magliocco, Molecular Testing and the Pathologist's Role in Clinical Trials of Breast Cancer. Clin Breast Cancer, 2016. 16(3): p. 166-79.

4. Rocken, C., Quality assurance in clinical trials--the role of pathology. Virchows Arch, 2016. 468(1): p. 83-92.

5. Edwards, J., et al., Human tissue models for a human disease: what are the barriers? Thorax, 2015. 70(7): p. 695-7.

6. The Royal College of Pathologists. The retention and storage of pathological records and specimens (5th edition). 2015; Available from:

https://www.rcpath.org/resourceLibrary/the-retention-and-storage-of-pathologicalrecords-and-specimens--5th-edition-.html.

7. Fairley, J.A., K. Gilmour, and K. Walsh, Making the most of pathological specimens: molecular diagnosis in formalin-fixed, paraffin embedded tissue. Curr Drug Targets, 2012. 13(12): p. 1475-87.

8. Gnanapragasam, V.J., Unlocking the molecular archive: the emerging use of formalinfixed paraffin-embedded tissue for biomarker research in urological cancer. BJU Int, 2010. 105(2): p. $274-8$.

9. Cree, I.A., et al., Guidance for laboratories performing molecular pathology for cancer patients. J Clin Pathol, 2014. 67(11): p. 923-31. 
10. Lim, C., et al., Biomarker testing and time to treatment decision in patients with advanced nonsmall-cell lung cancer. Ann Oncol, 2015. 26(7): p. 1415-21.

11. Human Tissue Authority. Information for research tissue banks. 2015; Available from: https://www.hta.gov.uk/policies/information-research-tissue-banks.

12. Fitzgibbons, P.L., Are there barriers to the release of paraffin blocks for clinical research trials? A College of American Pathologists survey of 609 laboratories. Arch Pathol Lab Med, 2011. 135(7): p. 870-3.

13. Eysenbach, G., Improving the quality of Web surveys: the Checklist for Reporting Results of Internet E-Surveys (CHERRIES). J Med Internet Res, 2004. 6(3): p. e34.

14. Cancer Research UK. Testing Times to Come? An Evaluation of Pathology Capacity Across the UK. 2016; Available from:

https://www.cancerresearchuk.org/sites/default/files/testing_times_to_come_nov_ 16_cruk.pdf.

15. Williams, B.J., et al., Digital pathology access and usage in the UK: results from a national survey on behalf of the National Cancer Research Institute's CM-Path initiative. J Clin Pathol, 2018. 71(5): p. 463-466.

16. The Royal College of Pathologists. Guidance on inter-departmental dispatch of cellular pathology material for referral and clinical trials. 2016; Available from: https://www.rcpath.org/resourceLibrary/g137-interdeptdispatch-sep16.html. 


\section{Figure legends}

Figure 1 - Selection of sample to send away when asked to submit tissue for clinical trial research.

Figure 2 - Selection of sample to send away when asked to submit slides for clinical trial central review.

Figure 3 - Responses relating to whether there is a duty on pathology departments to maintain tissue for future diagnostic tests.

Figure 4 - The proportion of requests for tissue that originate from industry (as opposed to from academia).

Figure 5 - Funding sources supporting staff and infrastructure to respond to requests for tissue release (NHS - National Health Service, BRC - National Institute for Health Research Biomedical Research Centre).

Figure 6 - Consent checking prior to release of tissue for clinical trial research. 


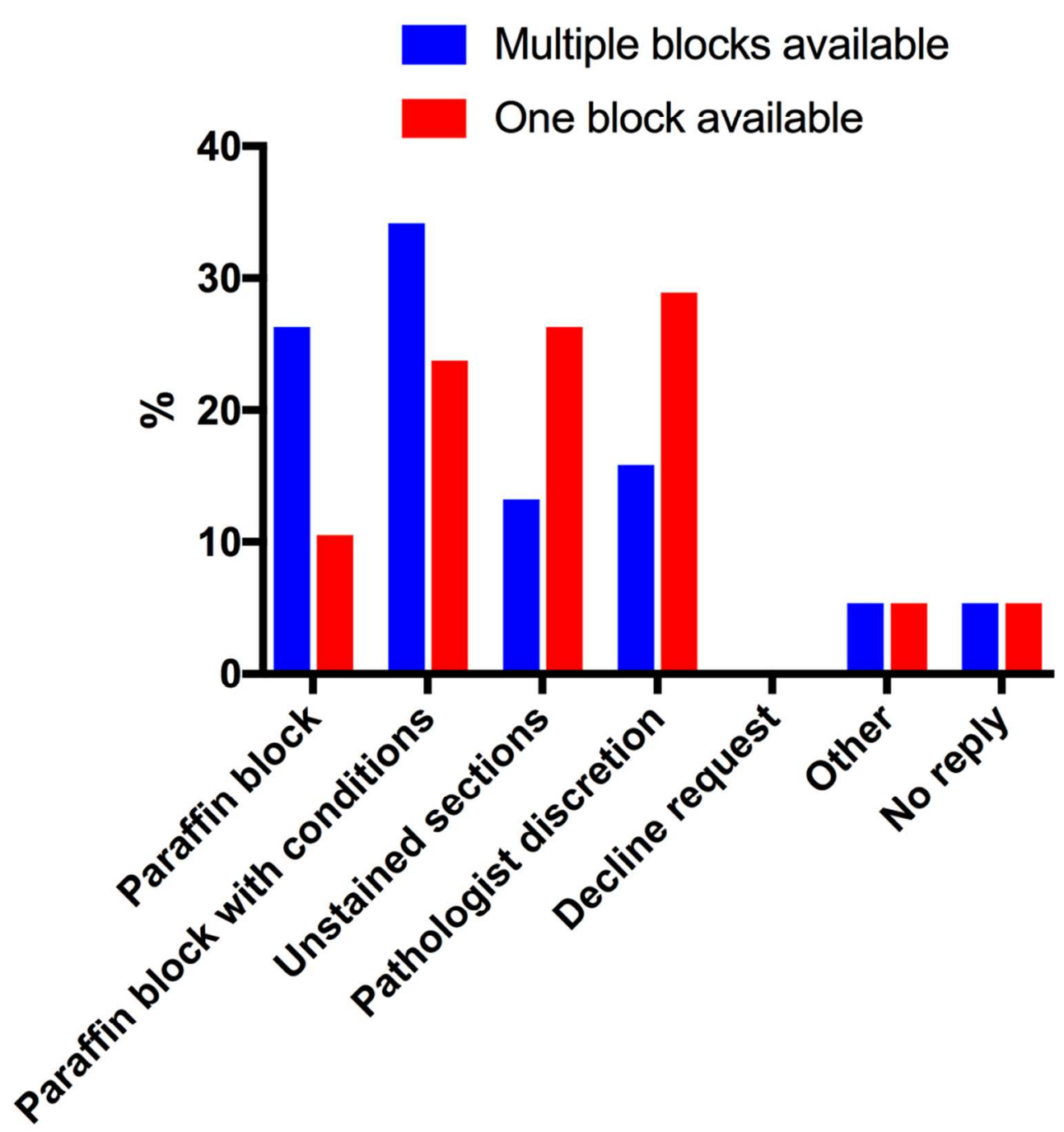

Figure 1 - Selection of sample to send away when asked to submit tissue for clinical trial research. $90 \times 95 \mathrm{~mm}(300 \times 300 \mathrm{DPI})$ 

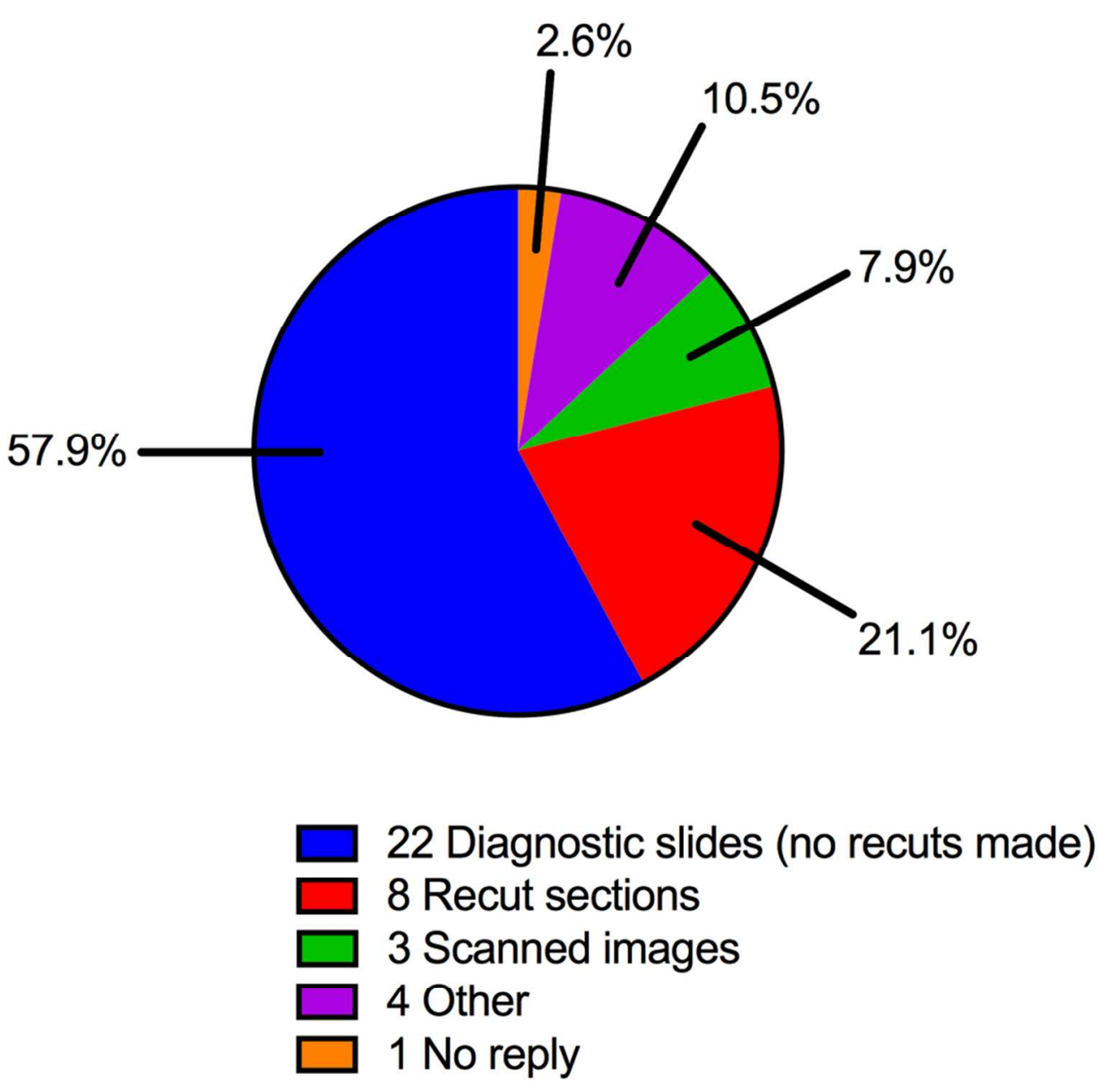

Figure 2 - Selection of sample to send away when asked to submit slides for clinical trial central review. $90 \times 88 \mathrm{~mm}(300 \times 300 \mathrm{DPI})$ 

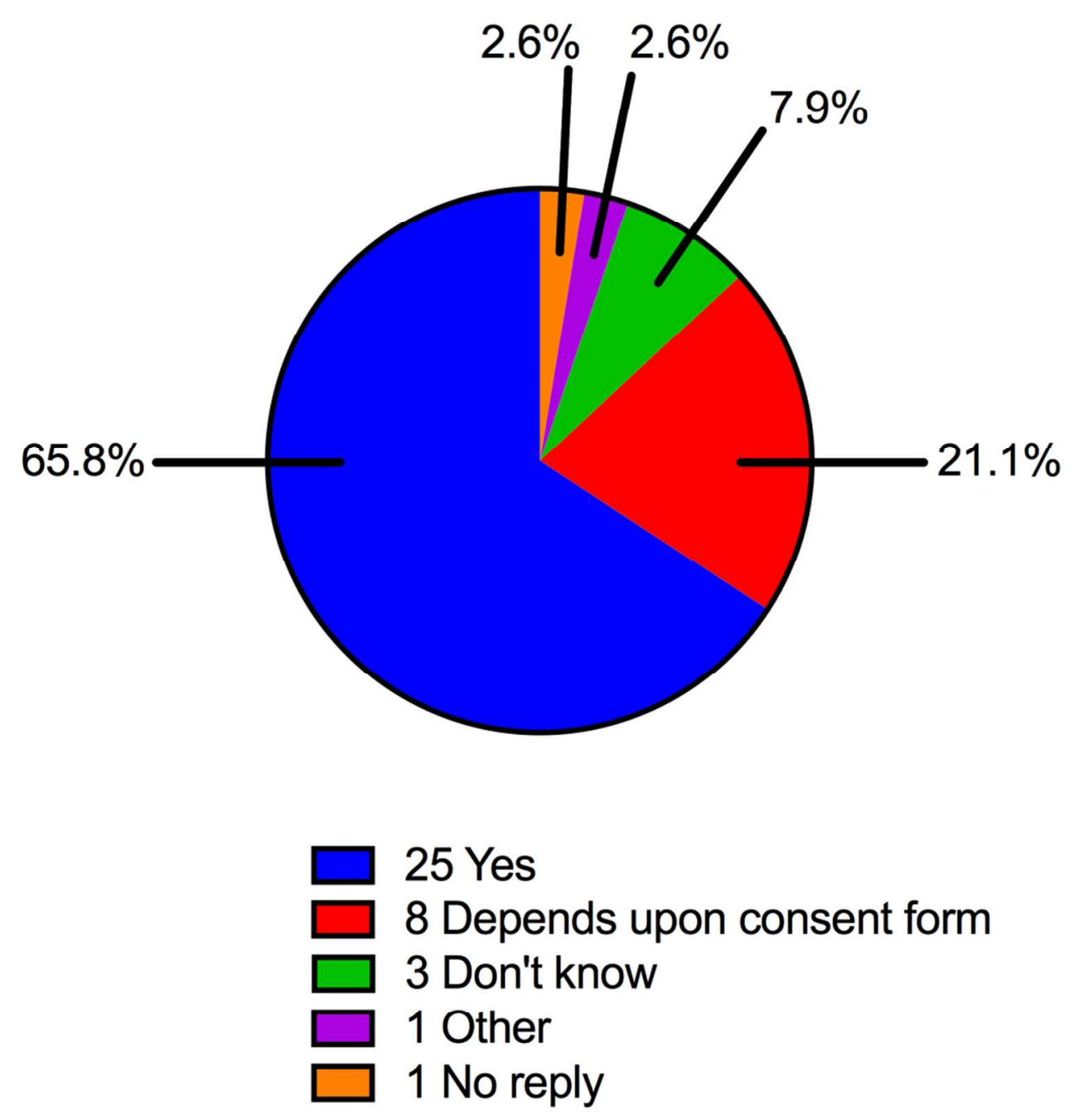

Figure 3 - Responses relating to whether there is a duty on pathology departments to maintain tissue for future diagnostic tests.

$90 \times 94 \mathrm{~mm}(300 \times 300 \mathrm{DPI})$ 


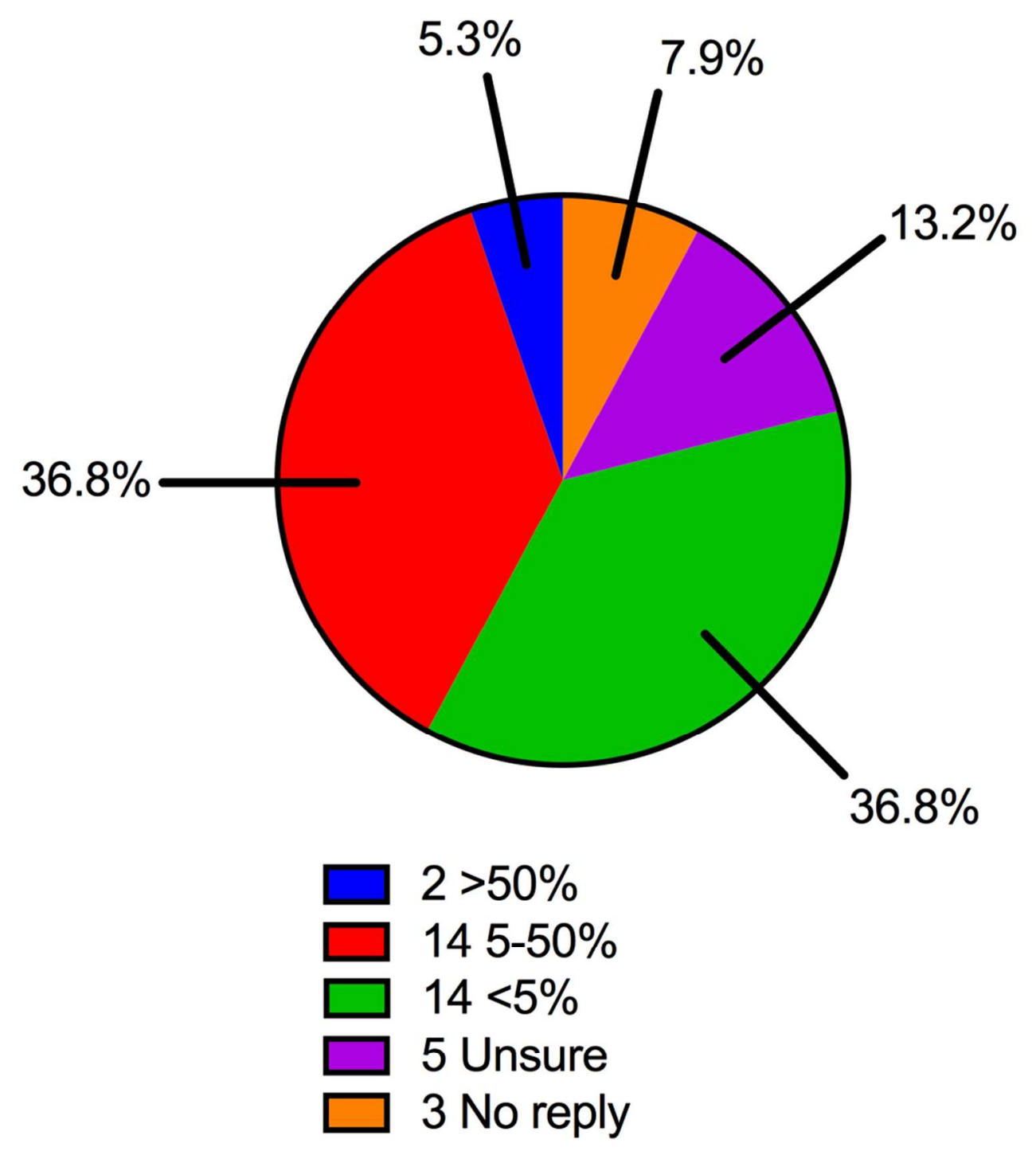

Figure 4 - The proportion of requests for tissue that originate from industry (as opposed to from academia). $90 \times 101 \mathrm{~mm}(300 \times 300$ DPI) 

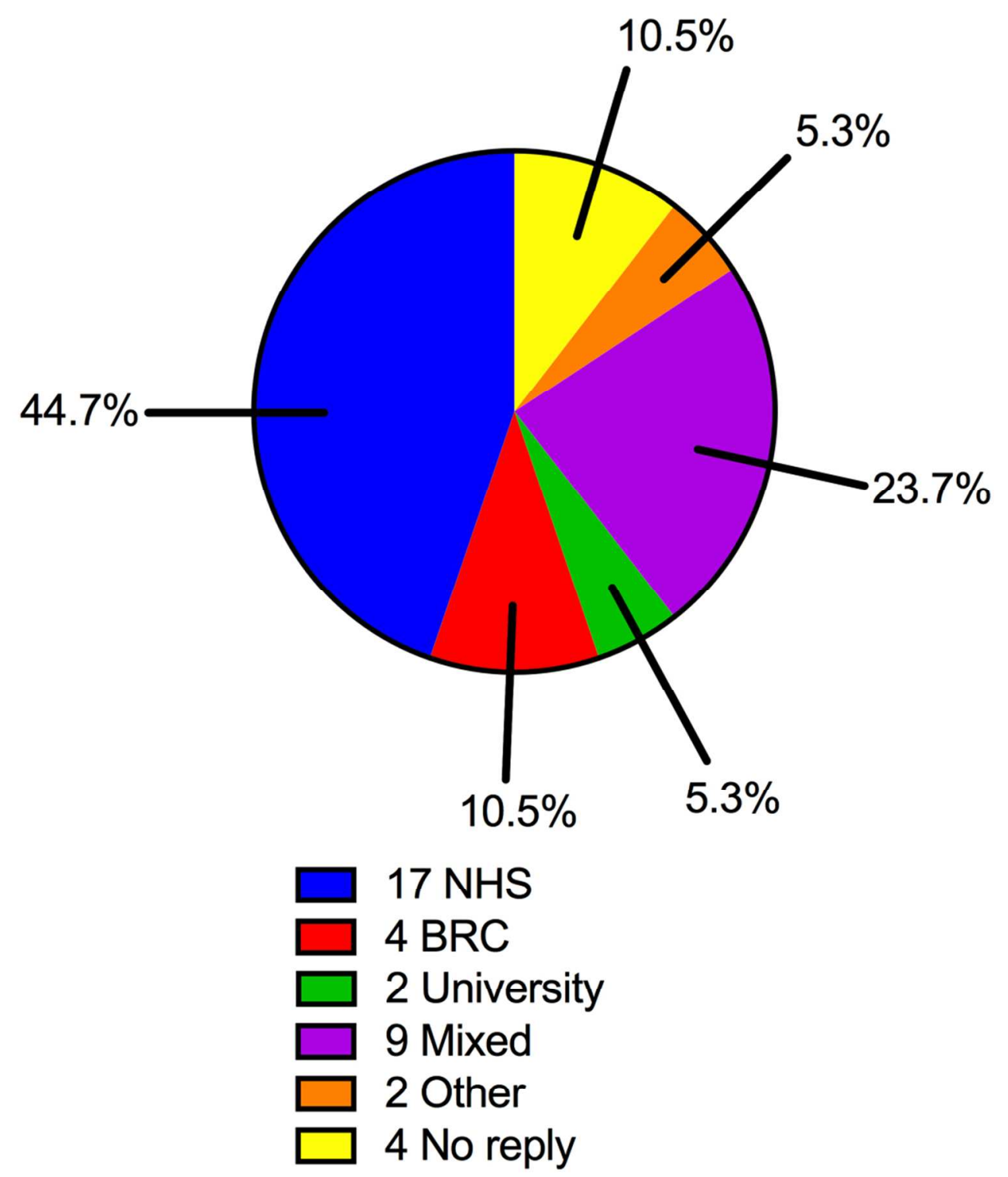

Figure 5 - Funding sources supporting staff and infrastructure to respond to requests for tissue release (NHS - National Health Service, BRC - National Institute for Health Research Biomedical Research Centre).

$90 \times 106 \mathrm{~mm}(300 \times 300 \mathrm{DPI})$ 

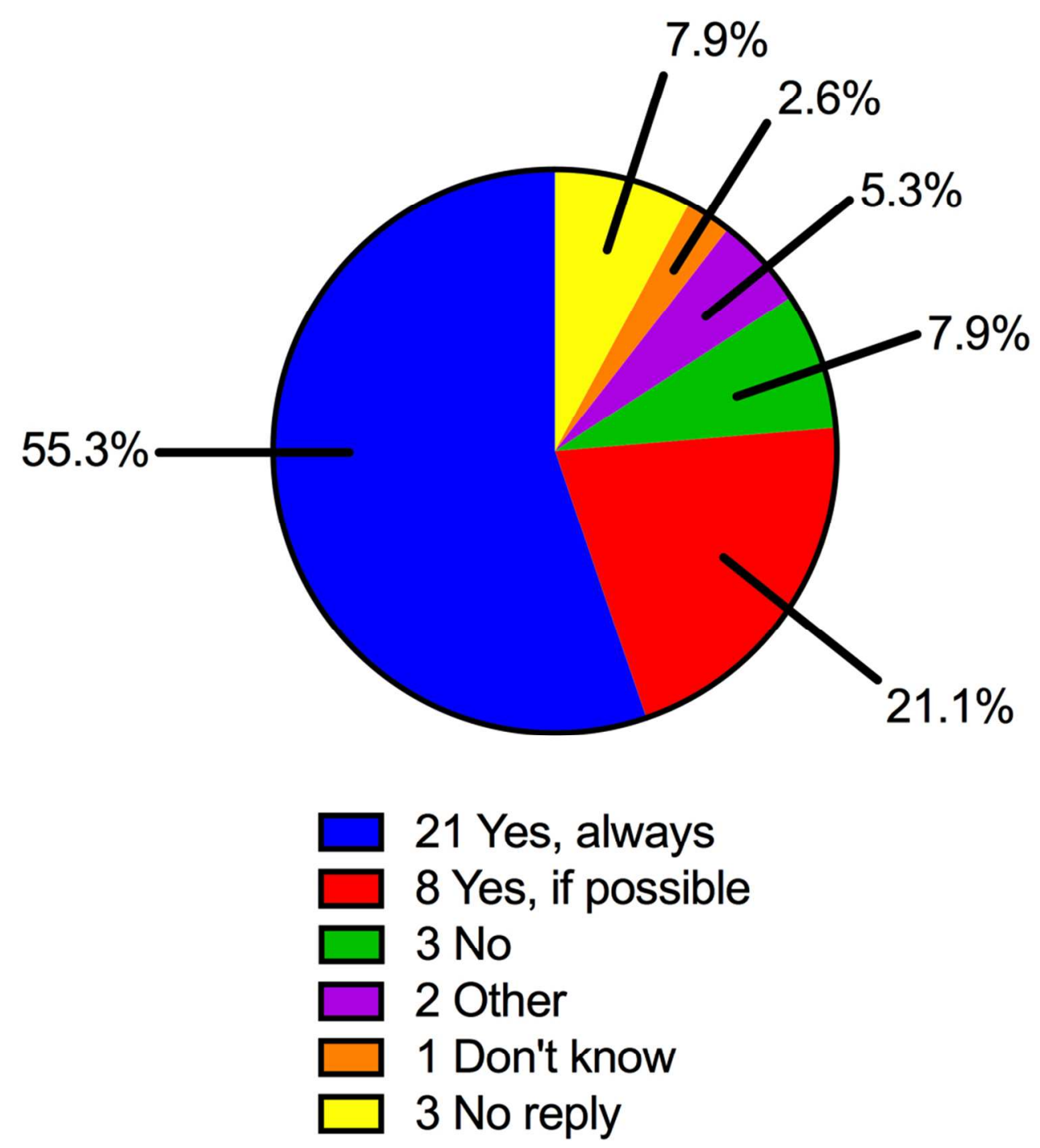

Figure 6 - Consent checking prior to release of tissue for clinical trial research. $90 \times 100 \mathrm{~mm}(300 \times 300$ DPI $)$ 


\section{Appendix 1-Questionnaire}

Background information - respondents

1. Hospital/institution name

2. Job title of person completing the questionnaire

3. Details of your responsibility for release of diagnostic archive material for research

Clinical head of department

Histopathology department manager

Tissue access committee chair (or equivalent)

Other (please specify)

Background information - tissue archives

4. Where are your diagnostic archives located?

On-site

Off-site (i.e. in a dedicated storage facility)

On- and off-site (i.e. recent material on-site, older off-site)

Other (please specify)

5. If your archives are off-site or partially off-site, is this a barrier to research?

$$
\begin{aligned}
& \text { Yes } \\
& \text { No } \\
& \text { Don't know }
\end{aligned}
$$

6. If your archives are off-site (or partially off-site), what is the cost of retrieving one standard case (standard size slide[s] plus block[s] [i.e. no large slides])?

7. Are your diagnostic archives covered by a Human Tissue Authority (HTA) licence? Yes 
No

Don't know

Tissue access

8. How often does your department receive requests to submit materials for research studies?

Regularly (i.e. several requests per month)

Occasionally (i.e. once per month)

Never

9. Do you have a tissue access committee (or equivalent) to evaluate requests to release tissue (including diagnostic archive material) for research?

Yes (please provide brief details, e.g. how often does it meet, what is the membership?)

No

Don't know

10. When receiving a request (with appropriate consent) to send tissue as part of a clinical trial and there are multiple blocks of the relevant lesion available, what is the most common response by your department?

Usually comply by submitting the paraffin block

Usually comply by submitting the paraffin block, but with conditions (e.g. must be available for return if required and tissue must not be exhausted)

Usually comply by submitting unstained sections

Use pathologist discretion as to whether to send the block

Decline all such requests 
Other (please specify)

11. When receiving a request (with appropriate consent) to send tissue as part of a clinical trial and only one block is available, what is the most common response by your department?

Usually comply by submitting the paraffin block

Usually comply by submitting the paraffin block, but with conditions (e.g. must be available for return if required and tissue must not be exhausted)

Usually comply by submitting unstained sections

Use pathologist discretion as to whether to send the block

Decline all such requests

Other (please specify)

12. When receiving a request to send diagnostic slides for central review (or other purpose) for a clinical trial, what is the most common response by your department?

Usually comply by submitting the diagnostic slides (no recuts made)

Usually comply by submitting recut sections and keeping the original diagnostic sections in your department

Usually comply by submitting the original diagnostic slides and keeping recuts in the department

Usually comply by submitting scanned images of the original diagnostic slides

Decline all such requests

Other (please specify)

13. If there was a mechanism to quickly and easily retrieve blocks upon request or you could be sure that the tissue would not be exhausted, would that change your institution's willingness to send blocks? 


$$
\begin{aligned}
& \text { Yes } \\
& \text { No } \\
& \text { Don't know }
\end{aligned}
$$

14. Is release dependent on the reporting pathologist giving permission?

$$
\begin{aligned}
& \text { Yes } \\
& \text { No } \\
& \text { Don't know }
\end{aligned}
$$

15. Do you believe that there is a duty on pathologists and pathology departments to maintain diagnostic material in a pathology department for future diagnostic tests that may be required or are developed in the future?

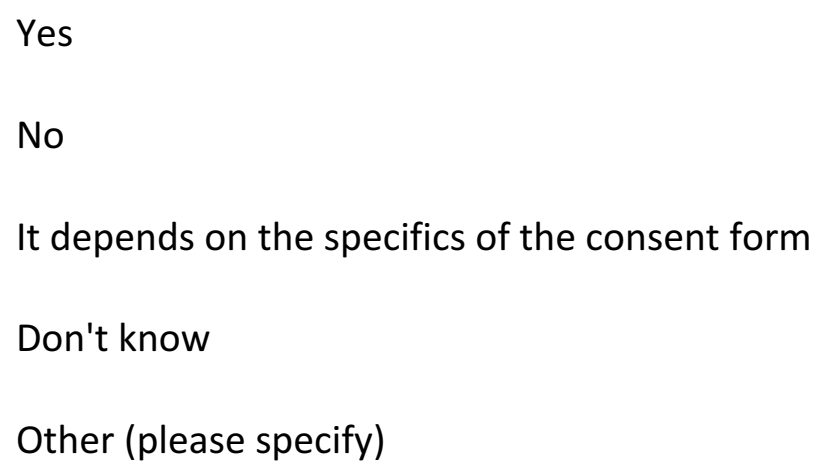


Other (please specify)

18. Do you charge for scanning sections for a trial?

Yes (please specify cost)

No

No (have no access to scanner)

Other (please specify)

19. If you charge for sending materials for research, have the costs been factored in to the research study?

Always

Mostly

Sometimes

Never

Other (please specify)

20. What percentage of tissue access requests originate from industry rather than academia?

Over $50 \%$

$5-50 \%$

Less than $5 \%$

Unsure

21. Do your tissue access costs differ for industry requests versus academic requests?

Yes, industry is charged more than academic requestors

Yes, industry is charged less than academic requestors

No, they are charged the same 
22. Would you still charge if the trial was on the National Institute for Health Research (NIHR) trial portfolio?

Yes

No

Other (please specify)

23. How are the staff and infrastructure that fulfil research requests funded?

University

Biomedical Research Centre (BRC)

National Health Service (NHS)

Mixed

Other (please specify)

\section{Consent issues}

24. Does your institution have a system of collecting consent wishes in relation to surplus diagnostic material when patients are undergoing surgery on the NHS consent to procedure form?
Yes
No
Not sure

25. If you answered yes to the above question, which best describes the system?

Robust

Variable

Unreliable

Other (please specify) 
26. Does your institution have a specific biobank consent form that can be used for surplus diagnostic material?

Yes

No

Not sure

27. For clinical trials, do you ask to see the consent form before releasing tissue?

$$
\begin{aligned}
& \text { Yes - always } \\
& \text { Yes - if possible } \\
& \text { No } \\
& \text { Don't know } \\
& \text { Other (please specify) }
\end{aligned}
$$

28. For research studies that are not related to a clinical trial, would you require evidence of consent before releasing diagnostic archive material? Please select one which best applies to your department.

Yes - always

Yes - if possible

No

Not necessarily if release is for a Research Ethics Committee (REC) approved project, the material is from the living and released anonymously (and you are sure the patient didn't decline)

Don't know

Other (please specify)

Other information (free text responses) 
29. Do you experience any other problems related to submission of materials for clinical trials or other research studies?

30. Are there any additional comments that you would like to make relating to this topic in general? 


\section{Appendix 2-Improving the quality of Web surveys: the Checklist for Reporting Results of Internet E-Surveys (CHERRIES)}

1. Design

- Given the importance of tissue release for clinical trial research, and to understand why this is not always achieved, the National Cancer Research Institute's (NCRI) Cellular Molecular Pathology (CM-Path) initiative decided to survey the UK's cellular pathology laboratories to ascertain current attitudes and practices in this area.

2. Institutional Review Board approval and informed consent process

- As this survey was not circulated to patients, the study did not require Institutional Review Board approval.

- Participants were informed that completion of the survey was voluntary and would take about 10 minutes, that the data would be stored and analysed by individuals working for the NCRI and that they would be used to contribute to the development of guidelines to standardise tissue release for clinical trials research.

- At the end of the survey period, all data were downloaded from the website hosting the survey and stored securely.

3. Development and pre-testing

- Our survey was developed by CM-Path Clinical Trials workstream members, based on their own experiences and a similar study conducted in the United States of America (USA) [12].

- It aimed to assess: (1) current attitudes and practices; (2) financial implications; and (3) barriers to tissue release. 
- The usability and technical functionality of the electronic questionnaire were tested by workstream members before survey dissemination.

4. Recruitment process and description of the sample having access to the questionnaire

- This was a closed survey, with invitations to participate distributed through the NCRI's CM-Path and Confederation of Cancer Biobanks (CCB) mailing lists.

- As the aim was to assess nationwide practice, responses were sought on a departmental/institutional basis; to achieve this, the questionnaire asked for the most appropriate individual in each department to complete it.

- We did not specify who this should be but suggestions of a tissue access committee chair or head of department were provided.

5. Survey administration

- The questionnaire was administered with the use of an online survey tool (www.surveymonkey.com).

- The survey was voluntary and no incentives were offered to complete it.

- The questionnaire was distributed in November 2016, with results analysed in August 2017.

- The survey contained 30 questions spread over 5 pages.

- Randomisation of items and adaptive questioning were not used.

- Whilst non-response options (e.g. 'not applicable'/'rather not say') were not provided, none of the questions were mandatory and all contained a 'don't know' or 'other' response option which permitted the entry of a free text answer. 
- Respondents were able to review and change their answers through the use of a 'Back' button.

6. Response rates

- 220 departments/institutions included in the NCRI's CM-Path and CCB mailing lists received an invitation to participate in the survey.

- We received 44 responses; with the majority of the UK's teaching hospitals replying we believe that our data accurately represent the practices of departments involved in large scale clinical research.

- Responses were received from throughout the UK (including England, Wales, Scotland and Northern Ireland).

7. Preventing multiple entries from the same individual

- Duplicate responses from a single department/institution were identified through a combination of the answers provided (e.g. department/institution name) and Internet Protocol (IP) address.

- Only the response from the individual deemed most appropriate by the authors was used in calculating summary statistics.

- 44 individuals completed the survey, representing 38 different departments/institutions.

- 6 duplicate responses were excluded from quantitative analyses $(n=38)$ but were included in qualitative analyses $(n=44)$.

8. Analysis 
- All non-duplicate questionnaires $(n=38)$, including two that were terminated mid-way through, were included in the final quantitative analysis.

- Where possible, simple summary statistics were calculated to display the response to each question.

- For questions that permitted free text responses, a summary of replies was provided. 